\title{
Ovipositional behaviour of two mango fruit fly species (Diptera Tephritidae) in relation to Oecophylla cues (Hymenoptera Formicidae) as compared to natural conditions without ant cues
}

\author{
Jean-François VAYSSIERES ${ }^{{ }^{1 *}}$, Antonio SINZOGAN ${ }^{2}$, \\ Appolinaire ADANDONON ${ }^{3}$, Paul VAN MELE ${ }^{4}$ and Sam KORIE ${ }^{5}$

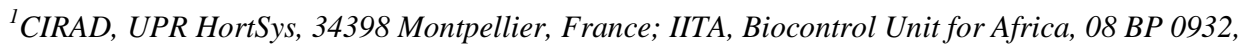 \\ Cotonou, Benin. \\ ${ }^{2}$ Faculté des Sciences Agronomiques, Université d'Abomey Calavi, BP 526 Cotonou, Bénin. \\ ${ }^{3}$ Ecole Nationale Supérieure des Sciences et Techniques Agronomiques (ENSTA) de Kétou, \\ Université d'Abomey-Calavi, BP 526 Cotonou, Bénin. \\ ${ }^{4}$ Agro-Insight, 9000 Ghent Belgium; formerly at Africa Rice Center, 01 BP 2031 Cotonou, Benin. \\ ${ }^{5}$ IITA-Ibadan, IITA Ltd., Carolyn House, 26 Dingwall Road, Croydon CR9 3EE, UK. \\ *Corresponding author, E-mail: j.vayssieres@cgiar.org; IITA 08 BP 0932, Cotonou, Benin. \\ fax (229) 213505 56; Tel (229) 21350188
}

\begin{abstract}
The tritrophic interactions between mangoes (Mangifera indica), two frugivorous fly species of great economic significance, Bactrocera invadens and Ceratitis cosyra, and weaver ants (Oecophylla longinoda) were studied in Benin. We investigated whether Oecophylla cues affect B. invadens and $C$. cosyra oviposition behaviour compared to natural conditions. Results show that on un-marked fruits, both $C$. cosyra and $B$. invadens adults have different active periods and length of oviposition, both under laboratory and field conditions. Compared to their landing on unmarked fruits at $7 \mathrm{~h}$ after confinement, $46 \%$ of $B$. invadens refrained from landing on fruits marked with Oecophylla cues, while C. cosyra reduced its landing by $73 \%$. In contrast to the un-marked fruit, both tephritid species significantly reduce oviposition duration and oviposited less in fruits when weaver ants had patrolled on them before. Moreover, no significant difference was detected between $C$. cosyra and $B$. invadens, in number of pupae produced, when confined with ant-marked fruits. Ecological and behavioural implications of our observations are discussed.
\end{abstract}

(C) 2013 International Formulae Group. All rights reserved.

Keywords: Mango fruit flies, oviposition duration, predator avoidance, weaver ants, biocontrol.

\section{INTRODUCTION}

Extrinsic information plays an essential role in the survival of insects. This includes: cues on the availability of food and mates, abiotic factors (e.g., temperature, relative humidity, wind, shelter) and biotic factors such as intra- or inter-specific competitors and other natural enemies, such as predators and parasitoids (Dicke and Grostal 2001). Many prey species have evolved chemical senses such as olfaction and taste for detecting their predators. Cues of predator presence may be emitted by the predators either directly [e.g., chemicals (kairomones) (Dicke and Sabelis, 1992)], or indirectly [e.g., chemicals from disturbed/injured (alarm pheromones) or dead conspecific arthropods (Rittschof and 
Hazlett,1997)]. Fruit flies have a strong adverse economic impact on commercial horticulture in tropical regions (Clarke, 2005). In Benin, losses for mango (Mangifera indica L.) crop cultivars of commercial interest due to fruit flies exceeded $50 \%$ by the middle of the crop season (Vayssières et al., 2009). In addition to direct losses, fruit flies are also quarantine pests leading to the destruction of many containers with mangoes exported from West Africa to Europe every year. In Benin, during the 2005 and 2006 mango seasons, losses due to two main fly species, Bactrocera invadens Drew-Tsuruta-White and Ceratitis cosyra (Walker), ranged from $17 \%$ to $73 \%$ (Vayssières et al., 2009). The first mentioned is an exotic species coming from Asia, only recently recorded in West Africa (Vayssières et al., 2005). The latter is a native species of Africa. To control fruit flies, growers sometimes resort to pesticides that are distributed for cotton production (Sinzogan et al., 2008). Uncommonly they resort to imported bait sprays (Lux et al., 2003). Control methods based on chemical pesticides are poorly effective because immature stages (eggs-larvae-pupae) are not killed by sprays and fly adults are scattered in the savannah around orchards. In addition, pesticides cause risks to public health and the environment. Considering the economic importance of fruit flies and the lack of appropriate control methods especially in sub-Saharian Africa, research efforts on alternative fruit fly control strategies are ongoing, including the use of biological control agents such as weaver ants. The workers of territorially-dominant arboreal ants deposit landmarks on their territories, something first shown in Oecophylla. This genus is represented by two species, Oecophylla longinoda (Latreille) (Hymenoptera, Formicidae) and Oecophylla smaragdina (Fabricius) (Hymenoptera Formicidae), from Africa and Australasia, respectively. All of the territorially-dominant arboreal ants studied exhibit a very efficient predatory behavior based on group ambush and provide good protection to their host trees (Dejean et al., 2007). Consequently, they have been used as biological control agents; $O$. smaragdina, in particular, was already used in ancient China on Citrus crops (Van Mele, 2008). Territorially-dominant arboreal ants not only directly protect their host trees from arthropod herbivores by preying on them, but also by repelling them (trait-mediated indirect interaction) (Offenberg et al., 2006); for example, Chrysomelidae beetles avoid laying eggs on plants when they perceive Oecophylla landmarks (Offenberg et al., 2004).

In Africa, O. longinoda is an arboreal ant with the most elaborated communication system that is recognized in ants (Offenberg, 2007). This weaver ant defends chemicallymarked territories at both intra and interspecific levels (Dejean et al., 2005). Oecophylla longinoda is aggressive and a common species among the rainforest canopy ants (Dejeanet ai., 2007). This weaver ant species is essential in agriculture because of its role in plant protection against insect pests including some families of Hemiptera (Miridae, Pentatomidae, Scutellaridae, Coreidae), Diptera (Tephritidae, Drosophilidae), Coleoptera (Curculionidae, Bostrichidae), Lepidoptera (Gracillariidae, Tortricidae) and Thysanoptera (Thripidae) on mango, citrus and cashew crops in Benin (Vayssières et al. unpublished data). In tropical countries, the weaver ant, Oecophylla spp., is increasingly recognized as a successful endemic natural enemy of fruit flies (Peng and Christian, 2006; Van Mele et al., 2007).

Following field observations in Benin, we know that (i) although we have occasionally observed weaver ants preying on $C$. cosyra and $B$. invadens adults, predation by ants on adult flies is scarce (Vayssières et al., 2006); (ii) predation is more important by ants on third larval 
instars when these maggots leave the rotten fruits to pupate in the soil (Vayssières et al., 2006; Socié, 2007). Van Mele et al. (2007) suggested that olfactory and visual factors could play a role in deterring these pests. This was confirmed by recent experiments (Adandonon et al., 2009; Van Mele et al., 2009). However, to our knowledge, detailed information is lacking in terms of ovipositional behaviour of $B$. invadens and $C$. cosyra and to which extent the behaviour of these two main species is influenced by the weaver ant cue effects. Moreover, little is known about the ovipositional behavioural response of the two fruit fly species when they forage on $O$. longinodaharbouring trees in orchards. The objective of this paper was to do comparative study of the effect of weaver ant cues on the ovipositional behaviour of two fruit fly species, B. invadens and C. Cosyra.

\section{MATERIALS AND METHODS}

Mango fruit "ant-marked" (with ant cue) vs. "unmarked" (without ant cue)

In March, 2008, 20 matured fruits of similar size were randomly collected from both ant-harboring and ant-free mango trees (cultivar Gouverneur approximately 20 years old), totally 40 fruits, from an orchard in Ouidah $\left(06^{\circ} 22^{\prime} .012^{\prime}{ }^{\prime} \mathrm{N}\right.$; 02 ${ }^{\circ} 4^{\prime} 59.988^{\prime}$ 'E) in southern Benin. Mangoes collected from the ant-inhabited trees were termed "antmarked", and those from ant-free trees were termed "unmarked". We presumed that fruits from ant-harbouring trees had been visited by ants. A tree was considered antfree when no weaver ants were observed under and in the tree.

\section{Fruit fly rearing}

Wild $B$. invadens and $C$. cosyra populations were established at the International Institute of Tropical Agriculture (IITA) in Cotonou, from the following infested fruits and localities: $M$. indica from Parakou and Psidium guajava L. from Tchatchou. Puparia collected with flexible tweezers were put into hatchery boxes for new adult emergence.

Adults from these puparia were held in screen cages $(42 \mathrm{~cm} \times 52 \mathrm{~cm} \mathrm{x} 52 \mathrm{~cm})$. Water, sugar and beer yeast (active ingredient: hydrolysate enzymatic autolyzed brewers yeast) (ICN Biomedicals, Inc.) were provided for the newly emerged adults to feed on. The beer yeast was provided as protein source (Plácido-Silva et al., 2005). Based on our personal observations in the laboratory, we considered the females of the genus Bactrocera and Ceratitis to have mated 12 and 10 days after emergence, respectively. Three gravid females of each species (B. invadens and C. cosyra) were carefully collected and moved into another screen cage to allow them to oviposit in mango fruits.

The fruit flies did not have any prior experience with weaver ants. During this greenhouse experiment, temperatures and relative humidity were daily recorded at the start of each observation at 9:00 and 15:00 using humidity/temperature pen (Extech Instrument $928527 \mathrm{CE}$, China). Data ranged from $26.3{ }^{\circ} \mathrm{C}$ to $28.5^{\circ} \mathrm{C}$ for temperatures and $69 \%$ to $82 \%$ for relative humidity, averaging $27.5^{\circ} \mathrm{C}$ and $78 \%$, respectively.

\section{Effect of ant-marked fruits on fruit fly oviposition behaviour}

Before being offered to $B$. invadens and $C$. cosyra, fruits were individually weighed and lightly punctured (100 punctures per fruit) using needle (ca $0,1 \mathrm{~mm}$ large hole). Punctures through the skin of the fruits facilitate oviposition (Papaj et al., 1989). Fruit flies were offered the marked and unmarked mangoes for three days, during which behaviour and oviposition observations were performed. Mango fruits were, in no choice experiment, individually put in cages and then confined with three gravid females of either $B$. invadens or $C$. cosyra.

Thus, the single fruit in the cage is offered to the three gravid females as did in early report in no-choice experiment (Adandonon et al., 2009). Fruits unconfined with flies were incubated for pupae emergence as initial field infestation 
(Initial), while pupae from the confined fruits were considered as greenhouse infestation.

There were 10 replicates per treatment. The oviposition behaviour was observed for $10 \mathrm{~min}$ (Nguyen et al., 2007) to record the number of times fruit flies landed on a fruit and the time they spent walking on the fruits. Observations were made (during the day) twice a day for three days (Van Mele et al., 2009) as follows: $1 \mathrm{~h}$ and $7 \mathrm{~h}$ (day 1), $25 \mathrm{~h}$ and $31 \mathrm{~h}$ (day 2), 49h and 55h (day 3 ), after flies and mango fruits were put together in the cage. In an additional experiment, other gravid fly females collected as described above were confined with marked and unmarked fruits (nochoice) and were also observed for $10 \mathrm{~min}$ at 49-h after confinement to record the time the fly spent to oviposit after it inserted its ovipositor into the fruit.

\section{Effect of ant-marked fruits on fruit fly number of pupae per $\mathrm{kg}$ fruits}

After 72 hours, the fruits were removed from the cages. Each fruit was individually placed on mesh supports mounted on basins with a fine net above to prevent larval escape (Vayssières et al., 2007). The bottoms of the basins were covered with wet sand, in which larvae emerging from the fruits could metamorphose into puparia. All fruits were placed at $27{ }^{\circ} \mathrm{C}$ during six weeks. Once a week, the sand of each container was sieved to collect and record the number of puparia.

\section{Behaviour of mango fruit flies in field conditions without weaver ants}

Females of both fruit flies, B. invadens and $C$. cosyra, were observed in the field. Two trees without weaver ants were selected and per tree, 30 mangoes were observed on the trees and 30 on the ground. Therefore, 60 mangoes were observed on the trees and 60 on the ground, in total 120 mangoes. Each mango was labelled and observed for 30 seconds at each observation, totally one hour observation for all the 120 mangoes.

Observations were done three times in May in 2009 and again three times in May in 2010 in Siné Dowirou's orchard in Tchatchou (Borgou Department in Central Benin). May is a month recorded in earlier experiments as a period when fruit fly populations build up in the field. Moreover, May is the period where both $B$. invadens and $C$. cosyra are abundant in mango orchards (Vayssières at al., 2009). Each of the 120 mangoes were observed for 30 seconds once every hour during the day, from 7:00 AM to 7:00 PM, during which number of fruit fly species ovipositing in the labelled fruits was recorded over one hour from each observation starting point (ie $7 \mathrm{~h}$ $8 \mathrm{~h}, 8 \mathrm{~h}-9 \mathrm{~h}, 9 \mathrm{~h}-10 \mathrm{~h}$, etc) on the marked fruits.

\section{Statistical analysis}

$\log 10(x+1)$ transformation was used to count variables to stabilize the variance and normalize the data. An analysis of variance was performed using the general linear model (GLM) procedure and mean separations were done using the StudentNewman-Keuls (SNK) option (SAS, 2003). A repeated mixed model ANOVA was also performed using fruit fly species and ants as factors, and mean separation was performed using least squares means.

\section{RESULTS}

\section{Oviposition behaviour under laboratory conditions}

At $7 \mathrm{~h}$ and $25 \mathrm{~h}$ after confinement with unmarked fruits, the number of times $B$. invadens landed was the same at both times while that of $C$. cosyra was different at these times (Figure 1). Once confined with marked fruits, the landing behaviour of fruit flies seems more species-dependant.

In general, the number of times each fly species landed on unmarked fruits after $7 \mathrm{~h}$ of confinement was significantly higher than that on ant-marked fruits $(F=12.25$; df $=1,239 ; P=0.0013$ ) (Figure 1 A). Ceratitis cosyra landed less on the ant-marked fruits than $B$. invadens. The repeated mixed 
model analysis showed that $C$. cosyra is close to be significantly twice as sensitive than $B$. invadens to the ant cues $(F=3.24$; df $=1,239 ; P=0.0733$ ). The pattern was quite similar for the time spent patrolling on mangoes by each fly species $(F=8.16$; df $=$ 1, 239; $P=0.023$ ) (Figure $1 \mathrm{~B}$ ). For instance, at $7 \mathrm{~h}$ and $25 \mathrm{~h}$ after confinement, $C$. cosyra landed twice and 1.6 times less, respectively than $B$. invadens (Figure 1). Compared to their landing on unmarked fruits at $7 \mathrm{~h}$ after confinement, $B$. invadens refrained from landing on marked fruits by $46 \%$, while $C$. cosyra reduced its landing by $73 \%$.

When comparing marked and unmarked fruits, the time fruit flies spent on the fruit $(F=26.05 ; \mathrm{df}=1,239 ; P<0.0001)$ and to oviposition $(F=23.01 ; \mathrm{df}=1,239 ; P$ $<0.0001$ ) was significantly higher on unmarked mango fruits than on marked fruits, irrespective of the fly species (Table 1). However, when comparing fruit fly species, a significant difference $(F=24.01$; df $=1,239 ; P<0.0001)$ was detected between species in terms of duration of oviposition only on unmarked fruits. Thus, while $B$. invadens oviposited in unmarked fruits for 6.3 minutes (in average), C. cosyra oviposited only 2.9 minutes (in average). In contrast, when on ant-marked fruit, no significant difference was detected between the two species in terms of time spent on fruit and for oviposition (Table 1).

\section{The effect of ant-marked fruits on fruit} fly number of pupae per $\mathrm{kg}$ fruits

The number of pupae per $\mathrm{kg}$ fruit followed a similar pattern to the oviposition behaviour. A significant difference was found between unmarked and ant-marked fruits $(F=46.15$; df $=1,239 ; P<0.001)$ (Table 2). The unmarked fruits (control) had six times more damage from $B$. invadens and four times more damage from $C$. cosyra compared to ant-marked fruits. Bactrocera invadens had a significantly higher number of pupae per $\mathrm{kg}$ fruit than $C$. cosyra when confined with unmarked mango fruits $(F=$ 46.15; df $=1,239 ; P<0.001)$ whereas no significant difference was detected between $C$. cosyra and $B$. invadens, when they were confined with ant-marked fruits (Table 2). Fruits unconfined with flies and incubated for pupae emergence as initial field infestation (Initial) showed no infestation (Table 2).

\section{Behaviour of fruit flies under field conditions without weaver ants}

The mean number of fruit flies observed ovipositing on fruits in May depended on the observation time in the day and was fruit fly species dependent. Figure 2 shows that $B$. invadens may oviposit during the whole day from 09:00 with two oviposition period peaks, one in the late morning (around 11:00) and the second in the afternoon (around 16:00). In contrast, even though $C$. cosyra was also observed in the field as $B$. invadens to oviposit from 09:00, less than four females of C. cosyra were observed ovipositing, which increased only after 16:00. Females of C. cosyra were more active than $B$. invadens in ovipositing after 17:00. A difference between the two fly species was found for the oviposition time on mango trees without ants.

Table 1 Fruit fly behaviour on ant-marked and unmarked fruits.

\begin{tabular}{lcccc}
\hline \multirow{2}{*}{ Treatment } & \multicolumn{2}{c}{ Duration of oviposition (minutes) } & \multicolumn{2}{c}{ Time spent on fruit (minutes) } \\
\cline { 2 - 5 } & B. invadens & C. cosyra & B. invadens & C. cosyra \\
\hline Unmarked & $6.3 \pm 0.58^{\mathrm{a}}$ & $2.9 \pm 0.41^{\mathrm{b}}$ & $8.1 \pm 0.62^{\mathrm{a}}$ & $6.3 \pm 0.92^{\mathrm{b}}$ \\
Ant-marked & $0.1 \pm 0.05^{\mathrm{c}}$ & $0.2 \pm 0.13^{\mathrm{c}}$ & $1.0 \pm 0.25^{\mathrm{c}}$ & $0.6 \pm 0.27^{\mathrm{c}}$ \\
\hline
\end{tabular}

Each value is a mean $( \pm 1 \mathrm{SE})$ of 10 replicates. Values followed by a different letter are significantly different $(P<0.05)$ according to repeated mixed model ANOVA and least squares means (Adandonon et al, 2009). 
Table 2: Fruit fly damage in ant-marked and unmarked fruits.

\begin{tabular}{|c|c|c|c|}
\hline \multirow[t]{3}{*}{ Treatment } & \multicolumn{3}{|c|}{ Number of pupae / kg fruit } \\
\hline & \multirow[t]{2}{*}{ Initial* } & \multicolumn{2}{|c|}{ Final } \\
\hline & & B. invadens & C. cosyra \\
\hline Unmarked & 0 & $65.04 \pm 3.19^{\mathrm{a}}$ & $44.88 \pm 3.32^{b}$ \\
\hline Ant-marked & 0 & $9.65 \pm 1.33^{c}$ & $10.28 \pm 1.33^{\mathrm{c}}$ \\
\hline
\end{tabular}

*Number of pupae from fruits collected in the field orchard and incubated for initial infestation. Each value is a mean of 10 replicates followed by its standard error. Values followed by a different letter are significantly different $(P<0.05)$ according to GLM using Student-Newman-Keuls test (Adandonon et al., 2009).
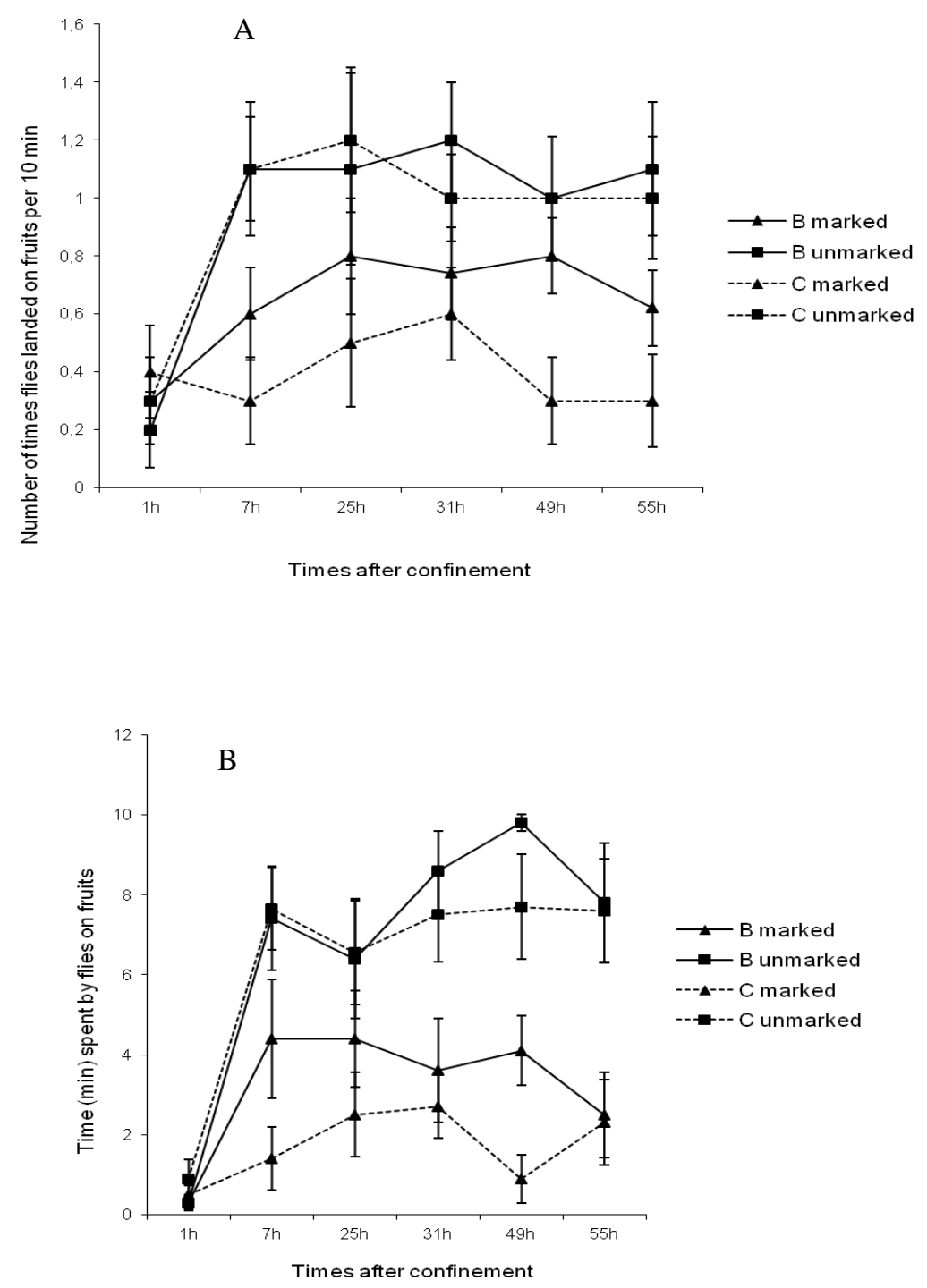

Figure 1: Effects of exposure to a cue-complex of Oecophylla longinoda on fruit fly oviposition behaviour in relation to fly species. (A) The number of times flies landed on marked and unmarked mangoes; (B) The time spent per fruit fly walking on marked and unmarked mangoes (repeated mixed model ANOVA and least squares means). Values are means $\pm 1 \mathrm{SE}$. "B or C marked" stand for Bactrocera or Ceratitis confined with ant-marked fruits while "B or C unmarked" stand for Bactrocera or Ceratitis confined with unmarked fruits. 


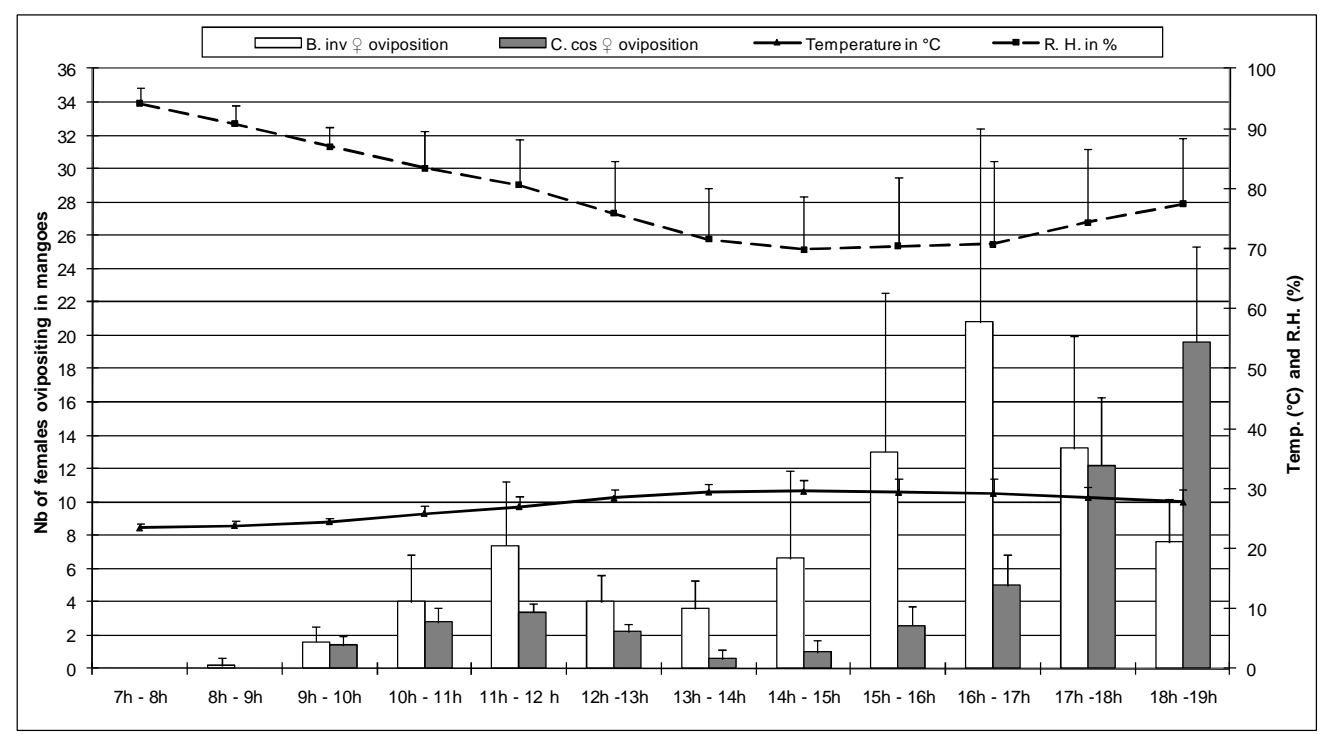

Figure 2: Oviposition behaviour during the day in terms of mean number of females of $B$. invadens and $C$. cosyra ovipositing on Mangifera indica (cultivar Eldon) fruits in an orchard in Tchatchou in relation to temperature and relative humidity (as R.H. \%) in the second axis title in May 2009-2010. Data are the mean $\pm \operatorname{SE}(\mathrm{n}=30)$.

\section{DISCUSSION}

Important factors that are known to affect fruit fly oviposition behaviour are host species, host quality, genetics, learning, potential fecundity and general life history, social context, fly species and also the chemical context (Jang et al., 1997; Brévault and Quilici, 2007). In our experiment, fruit host species and host quality were the same. In terms of fly species, in previous field study, B. invadens females used more time $(\sim 5$ minutes) than $C$. cosyra females ( $\sim 3$ minutes) for oviposition. In fact, this roughly corresponds with what we have observed in the mango orchards during the past mango seasons (2005-2008) in the Department of Borgou in Benin. The time for oviposition by $B$. invadens could be a little longer (in the field) than 5 minutes in mangoes without ants at the vicinity. This is probably because each $B$. invadens female lays at least twice as many eggs per mango fruit as C. cosyra females do. Although both species can lay eggs from 09:00 in orchards without ants, the oviposition activity of $B$. invadens peaking twice in the day may be one of the factors contributing to its higher fecundity and prolific capacity compared to $C$. cosyra females which only have one peak ovipositioning period. Indeed, $B$. invadens is known to be more prolific than C. cosyra (Cugala and Magala, 2009) and $B$. invadens is really abundant in Benin from May onwards during the whole mango season (Vayssières et al., 2005).

When mangoes were ant-marked, no significant difference was detected between the two fruit fly species in terms of time spent on fruit and for laying eggs. Ant cues can be included in the series of environmental and physiological factors which can affect (Dukas et al., 2001; Leal et al., 2008) the several phases included in the ovipositional behaviour of fruit flies (Aluja et al., 2000).

Recalling the predatory avoidance hypothesis (Offenberg et al., 2004) and knowing that fruit fly oviposition behaviour is affected by ant cues (Adandonon et al., 2009; Van Mele et al., 2009), the questions remain what the underlying mechanisms are and how tephritid females, at first attracted by the ester volatiles of mangoes, become repelled from these fruits when ant cues are present. Papaj and Prokopy (1986; 1989) and Robacker and Fraser (2005) demonstrated that individuals of 
tephritid females can learn about oviposition sites and avoid laying eggs when they are unsure of the sites. Tephritid females which are inclined to accept a special fruit and reject others are significantly influenced in their behaviour by experience with these previous fruits (Prokopy et al., 1993). In our study, the tephritid females, either $B$. invadens or $C$. cosyra were newly emerged fruit flies from pupae reared in the laboratory and had no prior exposure to the "cue complex" of $O$. longinoda. So, the predatory avoidance might not be the consequence of learning. Two hypotheses could be formulated from the observed behaviour in this experiment. Firstly, the multi exocrine secretions (Bradshaw et al., 1979) of the ants may interfer with the effect of volatile esters of mangoes which attract fruit flies. This might explain the effect of the ant cues on the reduced landing frequency of both species with important reduced landing by $C$. cosyra. The second hypothesis could be of genetic origin which might be common to fruit flies, regardless of the species.

In the current study, C. cosyra seems to respond more to the cue presence on the fruits and refrains more from landing than $B$. invadens. We could advance that $C$. cosyra is more sensitive to ant cues than $B$. invadens probably because $C$. cosyra is an African fly species that has developed a strong predator avoidance response to cues of the African weaver ant $O$. longinoda. In this cue complex, the Asian fruit fly $B$. invadens might recognize only some of the similar components of the cue complex of the Asian weaver ant, $O$. smaragdina, and therefore responded less strongly. Further laboratory studies are needed in order to get more information about these two mango fruit fly species and the nature of the chemical composition of the cue. However, once on the marked fruits, both species seem to be equally affected by the ant cue, with no significant different in terms of times spent and time for oviposition on the fruit. This might indicate that once landed on the ant cue-marked fruits, the ant cue effect is species-independent. This is very important in terms of fruit fly control using weaver ants. When properly managed in an integrated pest management (IPM), the weaver ant leaving its cues while patrolling on fruits could deter any fruit fly species, and likely many insect species seeking an oviposition or feeding site.

The effect of cues from generalist predators, such as ants, on the foraging behaviour of frugivorous insects and more generally on pests in terrestrial systems is a recent finding (Offenberg et al., 2004; Van Mele et al., 2007; Adandonon et al., 2009, Offenberg et al., 2013). This is the first report on generalist predator cues comparing ovipositional behaviour of $B$. invadens and $C$. cosyra. Oviposition behaviour seems to be fruit fly species independent when ant cues are present, especially after fruit flies have landed on the ant cue-marked fruits. These findings are likely to have crucial consequences for future research on fruit fly and consequently on developing protection strategies (Van Mele 2008) and best bet technologies in IPM against these tephritid pests with focus on species aspects.

\section{ACKNOWLEDGMENTS}

We would like to thank Calice Delou and Cyril Akponon for their technical help. We are also grateful to the Conservation, Food and Health Foundation and to CIRAD for funding. Thanks are due to IITA-Cotonou and the Africa Rice Center. Many thanks also to Pierre François Duyck, Tim Möhlmann and Kris Wyckuys for reviewing an earlier version of the manuscript.

\section{REFERENCES}

Adandonon A, Vayssières J-F, Sinzogan A, Van Mele P. 2009. Density of pheromone sources of the weaver ant Oecophylla longinoda affects oviposition behaviour and damage by mango fruit flies (Diptera: Tephritidae). Int. J. Pest. Manage, 55: 285-292.

Aluja M, Piñero J, Jácome I, Díaz-Fleischer F, Sivinski J. 2000. Behavior of flies in the genus Anastrepha (Trypetinae: Toxotrypanini). In Fruit Flies (Tephritidae): Phylogeny and Evolution 
of Behavior, Aluja M, Norrbom AL (eds). CRC Press: New York; 375-410.

Bradshaw JWS, Baker R, Howse PE. 1979. Chemical composition of the poison apparatus secretions of the African weaver ant Oecophylla longinoda and their role in behaviour. Physiol. Entomol., 4: $39-46$.

Brévault T, Quilici S. 2007. Influence of habitat pattern on orientation during host fruit location in the tomato fruit fly, Neoceratitis cyanescens. B. Entomol. Res., 97: 637-642.

Clarke AR, Armstrong KF, Carmichael AE, Milne JR, Raghu S, Roderick GK, Yeates DK. 2005. Invasive phytophagous pests arising through a recent tropical evolutionary radiation: the Bactrocera dorsalis complex of fruit flies. Annu. Rev. Entomol., 50: 293-319.

Cugala DR, Mangana S. 2009. Establishment and Maintenance of Fruit Flies Pest Free Area and/or Pest Free Places of Production in Mozambique. Department of Plant Protection (NPPO): Maputo, Mozambique.

Dejean A, Solano PJ, Ayroles J, Corbara B, Orivel J. 2005. Arboreal ants build a trap to ambush and capture prey. Nature, 434 : 973.

Dejean A, Corbara B, Orivel J, Leponce M. 2007. Rainforest canopy ants: the implications of territoriality and predatory behaviour. Funct. Ecosyst. Commun., 1: 105-120.

Dicke M, Grostal P. 2001. Chemical detection of natural enemies by arthropods: An ecological perspective. Annu. Rev. Ecol. Evol. S., 32: 1-23.

Dicke M, Sabelis MW. 1992. Costs and benefits of chemical information conveyance: proximate and ultimate factors. In Insect Chemical Ecology: an Evolutionary Approach, Roitberg BJ, Isman MB (eds). Chapman \& Hall: New York; 122-155.

Dukas R, Prokopy RJ, Papaj DR, Duan JJ. 2001. Egg laying behavior of Mediterranean fruit flies (Diptera:
Tephritidae): is social facilitation important? Fla Entomol., 84: 665-671.

Jang EB, Carvalho LA, Stark JD. 1997. Attraction of female oriental fruit fly, Bactrocera dorsalis, to volatile semiochemicals from leaves and extracts of a nonhost plant, Panax (Polyscias guilfoylei) in laboratory and olfactometer assays. J. Chem. Ecol., 23: 1389-1401.

Leal TABS, Zucoloto FS. 2008. Oviposition behavior in wild Anastrepha obliqua (Macquart, 1835) (Diptera: Tephritidae): initial study of associative learning related to a protein source. Psychol. Neurosc., 1: 135-139.

Lux SA, Ekesi S, Dimbi S, Mohamed S, Billah M. 2003. Mango-infesting fruit flies in Africa: perspectives and limitations of biological approaches to their management. In Biological Control in IPM Systems in Africa, Neuenschwander $P$, Borgemeister C, Langewald J (eds). CABI Publishing: Wallingford USA; 277-294.

Nguyen VL, Meats A, Beattie GAC, SpoonerHart R, Liu ZM, Jiang L. 2007. Behavioural responses of female Queensland fruit fly, Bactrocera tryoni, to mineral oil deposits. Entomol. Exp. Appl., 122: 215-221.

Offenberg J. 2007. The distribution of weaver ant pheromones on host trees. Insectes Soc., 54: 248-250.

Offenberg J, Macintosh D, Nielsen MG. 2006. Indirect ant-protection against crab herbivory: damage-induced susceptibility to crab grazing may lead to its reduction on ant-colonized trees. Funct. Ecol., 20: 52-57.

Offenberg J, Nielsen MG, Macintosh DJ, Havanon S, Aksornkoae S. 2004. Evidence that insect herbivores are deterred by ant pheromones. Proc. $R$. Entol. Soc., 271: 433-435.

Offenberg J, Cuc NTT, Wiwatwitaya D. 2013. The effectiveness of weaver ant (Oecophylla smaragdina) biocontrol in Southeast Asian citrus and mango. Asian Myrmecol., 5: 139-149. 
Papaj DR, Prokopy RJ. 1986. Phytochemical basis of learning in Rhagoletis pomonella and other herbivorous insects. $J$ Chem Ecol., 12: 1125-1143.

Papaj DR, Prokopy RJ. 1989. Ecological and evolutionary aspects of learning in phytophagous aspects. Ann. Rev. Entomol., 34: 315-350.

Papaj DR, Katsoyannos BI, Hendrichs J. 1989. Use of fruit wounds in oviposition by Mediterranean fruit flies. Entomol. Exp. Appl., 53: 203-209.

Peng R, Christian K. 2006. Effective control of Jarvis's fruit fly, Bactrocera jarvisi (Diptera: Tephritidae), by the weaver ant, Oecophylla smaragdina (Hymenoptera: Formicidae), in mango orchards in the Northern Territory of Australia. International Journal of Pest Management, 52: 275-282.

Plácido-Silva MDC, Zucoloto FS JoachimBravo IS. 2005. Influence of protein on feeding behavior of Ceratitis capitata Wiedemann (Diptera: Tephritidae): comparison between immature males and females. Neotropical Entomology, 34: 539-545.

Prokopy RJ, Coley SS, Papaj D. 1993. How well can relative specialist Rhagoletis flies learn to discriminate fruit for oviposition? Journal of Insect Behaviour, 6: $167-176$.

Rittschof D. Hazlett BA. 1997. Behavioural responses of hermit crabs to shell cues, predators haemolymph and body odour. Journal of the Marine Biological Association of the United Kingdom, 77: 737-751.

Robacker DC, Fraser I. 2005. What do Mexican fruit flies learn when they experience fruit? Journal of Insect Behaviour, 18: 529-542.

SAS 2003. The SAS System for Windows, version 9.1 computer program. Cary, NC, SAS.

Sinzogan AAC, Van Mele P, Vayssières J-F. 2008. Implications of on-farm research for local knowledge related to fruit flies and the weaver ant Oecophylla longinoda in mango production. Int. J. Pest. Manag., 54: 241-246.

Socié R. 2007. Etude de la fourmi tisserande Oecophylla longinoda et de sa prédation sur les mouches des fruits dans le cadre de la mise en place d'un programme de lutte biologique. Master thesis, Montpellier 2.

Van Mele P. 2008. A historical review of research on the weaver ant Oecophylla in biological control. Agric. Forest Entomol., 10: 13-22.

Van Mele P, Vayssières J-F, Adandonon A, Sinzogan A. 2009. Ant cues affect the oviposition behaviour of fruit flies (Diptera: Tephritidae) in Africa. Physiol, Entomol., 34: 256-261.

Van Mele P, Vayssières J-F, Van Tellingen E, Vrolijks J. 2007. Effects of an African weaver ant, Oecophylla longinoda, in controlling mango fruit flies (Diptera: Tephritidae) in Benin. J. Econ. Entomol., 100: 695-701.

Vayssières J-F, Goergen G, Lokossou O, Dossa P, Akponon C. 2005. A new Bactrocera species in Benin among mango fruit fly (Diptera: Tephritidae) species. Fruits, 60: 371-377.

Vayssières J-F, Lokossou O, Ayegnon D, Akponon C. 2006. Inventaire, fluctuations des populations et importance des dégâts des espèces de mouches des fruits (Diptera: Tephritidae) inféodées au manguier dans le département du Borgou (Benin) en 2005 et 2006. Proc. Actes Atel. Sci. Nat., 1: $27-$ 34.

Vayssières J-F, Sanogo F, Noussourou M. 2007. Inventory of the fruit fly species (Diptera: Tephritidae) linked to the mango tree in Mali, and tests of integrated control. Fruits, 62: 329-341.

Vayssières J-F, Korie A, Ayegnon D. 2009. Correlation of fruit fly (Diptera: Tephritidae) infestation of major mango cultivars in Borgou (Benin) with abiotic and biotic factors and assessment of damage. Crop Prot., 28: 477-488. 